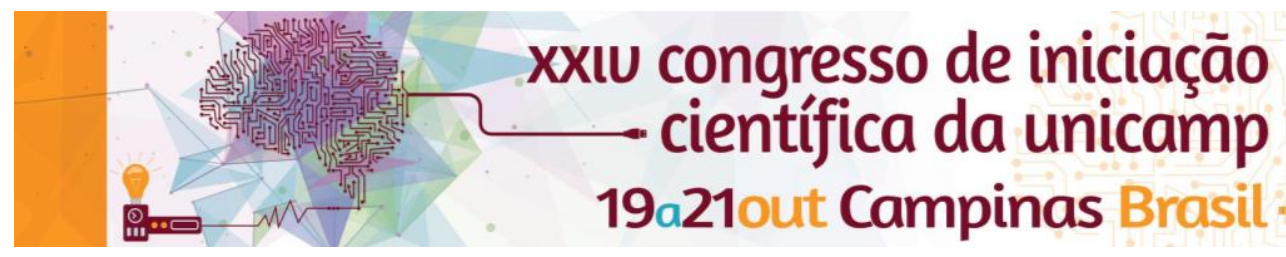

\title{
O papel do banco Kreditanstalt für Wiederaufbau (KfW) após a promoção do desenvolvimento na Alemanha
}

\author{
Aline Jorge Moraes*, Ana Rosa Ribeiro de Mendonça.
}

\begin{abstract}
Resumo
Historicamente, bancos de desenvolvimento têm atuado como instituições financeiras voltadas para o apoio a projetos que requeiram financiamento de longo prazo e tenham como objetivo a melhoria nas condições socioeconômicas de diferentes países. Como tal, têm sido associados à promoção da industrialização. Foi no segundo período pós-guerra que surgiram em grande número, quando os países ainda não industrializados começaram seus projetos de industrialização, ao mesmo tempo em que economias europeias maduras, porém destruídas, promoviam esforços de reconstrução. A Alemanha, fortemente arruinada pela Segunda Guerra Mundial, dentro deste esforço, criou, em 1948, o Kreditanstalt für Wiederaufbau (KfW), com o objetivo de promover o financiamento da reconstrução. A atuação da instituição foi, nos primeiros anos, vigorosa em projetos de indústria pesada, habitação e agricultura. Uma vez realizada essa tarefa, tendo cumprido seu objetivo inicial já na metade da década de 50 , o banco continuou e continua, ainda hoje, atuando de forma intensa. A instituição apresentou mudanças quanto a sua forma de organização, passando a se chamar KfW Bankengruppe (Grupo de Bancos KfW), com uma série de bancos especializados em cada área de atuação (como pequenas e médias empresas, ajuda internacional, etc.), e passou a atuar na promoção do desenvolvimento em países de quatro continentes: África, Ásia, América Latina e Europa. Além de apresentar essas mudanças internas, acompanhou as modificações nos papeis que os bancos de desenvolvimento apresentaram ao longo dos anos. Com a crise econômica e financeira de 2008, eles parecem ter desempenhado um comportamento anticíclico, tendo o $\mathrm{KfW}$ atuado nesse sentido para a rápida recuperação da economia alemã. O objetivo da pesquisa foi analisar o papel recente do KfW, passando pelo conceito, surgimento e evolução dos bancos de desenvolvimento, contexto histórico e sistema financeiro alemães e atuação do KfW durante e após a reconstrução do país.
\end{abstract}

\section{Palavras-chave:}

Bancos de desenvolvimento, Reindustrialização Alemã, KfW.

\section{Introdução}

Bancos de desenvolvimento têm um papel diferenciado dos outros bancos em geral, com fundamental importância no financiamento de projetos nos quais o setor privado não se vê motivado a participar: financiamentos de longo prazo, financiamentos para pequenas, médias e novas empresas, P\&D e transferência de tecnologia e know-how; em geral, patrocinam projetos que trazem benefício social ou econômico, não tendo, então, o lucro como foco principal (GUTH ${ }^{1}$, 2006; e BRUCK, 2001, apud. GUTH, 2006).

O período no qual o surgimento destas instituições mais se intensificou foi o pós-segunda guerra, quando da necessidade de financiar, com participação ativa do Estado, a industrialização na América Latina e na Ásia, países com independência recém-declarada, e os países europeus destruídos pela guerra (caso da Alemanha).

A propriedade do KfW é dividida entre a República Federal da Alemanha (80\%) e os estados (20\%). $10 \%$ seu funding tem por base recursos do governo e lucro próprio. Os outros $90 \%$, devido ao rating AAA, provêm do mercado de capitais internacional. (ARONOVICH \& FERNANDES ${ }^{2}$, 2006; e KFW BANKENGRUPPE)

O desenvolvimento alemão no pós-segunda guerra envolveu expansão industrial acelerada e políticas sociais, que geraram, logo na década de 1950, altas taxas de crescimento e aumento do bem-estar social.

Dessa forma, o objetivo geral deste estudo foi analisar o papel recente do banco de desenvolvimento alemão $\mathrm{KfW}$, procurando entender suas funções após o cumprimento de seu objetivo inicial. Para tanto, foram os objetivos específicos: pesquisar o conceito, definição atribuições, surgimento e evolução dos bancos de desenvolvimento; apresentar um contexto histórico da Alemanha do fim da segunda guerra mundial e período posterior; analisar a estrutura e evolução do sistema financeiro alemão, bem como a atuação do KfW dentro dele; e discutir o papel do KfW no e após o processo de reconstrução da economia alemã.

\section{Resultados e Discussão}

O KfW se reorganizou como instituição, direcionando cada área de atuação a uma subdivisão específica. Diversificou suas atividades nacionalmente $e$ as expandiu a diversos países.

\section{Conclusões}

Para continuar em plena atividade e como um dos maiores bancos da Alemanha, o $\mathrm{KfW}$ se adequou ao contexto de uma economia já industrializada, diversificando e ampliando seus objetivos e atribuições.

\section{Agradecimentos}

Agradeço à minha família, à minha orientadora, à Unicamp e ao CNPq, que proporcionaram o desenvolvimento dessa pesquisa.

${ }^{1}$ GUTH, Felipe Cerqueira. O BNDES nos anos 1990: uma análise keynesiana. UFRJ, 2006.

${ }^{2}$ ARONOVICH, Selmo, FERNANDES, Andréa Gomes. A atuação do governo no mercado de crédito: experiências de IFDs em países desenvolvidos. Revista do BNDES, Rio de Janeiro, v. 13, n. 25, p. 3-34, jun. 2006. 